\title{
INJURIES IN ASSOCIATION AND RUGBY FOOTBALL
}

\author{
Doris WEIGHTMAN ${ }^{1}$ and R. C. BROWNE, D.M., F.R.C.P. ${ }^{2}$ \\ University of Newcastle upon Tyne, Departments of Medical Statistics and Industrial Health \\ ${ }^{1}$ Assistant in Medical Statistics, ${ }^{2}$ Professor of Industrial Health
}

\begin{abstract}
The number, site, severity and rate of accidents and the medical attention received has been measured for association and rugby football in the four northern counties of England during the 1970-1971 season. 696 out of 1601 (43\%) association and 117 out of $232(50 \%)$ rugby football clubs replied to the questionnaires. If all the clubs had replied an estimated 14078 injuries would have occurred in association and 3888 in rugby football. For soccer, the accident rate was 36.5 per 10,000 man-hours of play and for rugger 30.5 . In soccer $65 \%$ of all injuries were to the lower limbs, but only $36 \%$ in rugger, which had a higher proportion of injuries to other sites compared with soccer. Fractures and dislocations were twice as common in rugger as in soccer. Concussion was also more common. In rugby football, the players are injured less often than in association football, but more seriously, as is shown by the fact that hospital treatment was needed by $\mathbf{2 9 . 8 \%}$ of the soccer injuries, but $\mathbf{5 2 . 8 \%}$ of those in rugby football. Similarly, a rugger injury needed on average 12 days off play, whereas one in soccer needed only 6 days off play.
\end{abstract}

A bigger proportion of soccer injuries (73.8\%) received rapid first aid than did rugger injuries $(45.8 \%)$. Better first aid cover at matches and simple protective clothing for the legs of soccer players and shoulders of rugby players are suiggested.

\section{Introduction}

Geiringer (1971) and Bannister (1972) have recently pointed out that, since we do not know the prevalance of injuries in the various sports, we are consequently impeded in our efforts to prevent them, or, indeed, to plan adequately for their treatment. Since the time of Napoleon, the British have changed from being a nation solely of shop keepers to being one of football players and watchers. It was decided, therefore, as part of a larger study of sports injuries in the four northern counties of England, to survey, as a first step, the incidence of injuries (and who treats them) in the two most popular sports - association and rugby football, for the $1970-71$ season.

An initial inquiry showed that no regular records were kept by football clubs so that the possibility of a retrospective study was ruled out from the first.

Northumberland, Durham, Westmorland and Cumberland were selected as survey areas, since they include both industrial and rural communities with all types of sports clubs and players.

The annual handbook of each sport provided the names and addresses of clubs and their secretaries. If clubs had moved or changed their names or their secretaries, the county sports secretaries were of considerable help in tracing them. Finally the clubs listed were as many as 1601 association and 232 rugby football clubs. Each of these was randomly allocated to one of the 9 months of the playing season of 1970-71, and stratified in such a way that there was no clumping of clubs from industrial or rural areas. Questionnaires on the prospective injury experience were sent to every club secretary to fill up for only a single month. This method kept the load of questionnaire filling to a minimum, but at the same time sampled the accident experiences evenly over the whole playing season. The questionnaire was designed as a simple one page form in two sections, to be completed for each accident. It contained information on the number of players and the hours for which they were at risk. The site and type of the injury, the date on which it happened, the medical attention which was given, and the length of time the player was off play were all noted. The club secretary's opinion of the medical attention at the time of the injury was also requested. In order to ensure the highest response rate, an explanatory letter was sent to each club secretary two weeks before the start of the month to which his club was allocated. A second letter, which contained the questionnaires, was sent just before the month to be surveyed. At the end of the survey month, a third letter, which contained a stamped, addressed envelope, was sent asking for the return of the forms. This letter also underlined the importance of completing a 'nil return' where appropriate. All the envelopes were white in colour, and were entitled "University of Newcastle upon Tyne Sports Council Injuries Survey" in bold red capital letters, in the top left hand corner.

$696(43 \%)$ of the 1601 association football clubs responded (four out of six professional) and $117(50 \%)$ of the $\mathbf{2 3 2}$ rugby clubs. Writing again to the clubs, who did not reply, met with little success. There was a postal strike in the middle of the survey and delayed postal packets were later sent with a short explanatory note 
about questionnaires which had to be completed retrospectively.

In discussing the ways of defining an injury, it had to be constantly borne in mind that the less work the club secretaries had to do in interpreting instructions before filling up the questionnaires the more likely we were to obtain their co-operation. Finally it was decided to let the questionnaire itself, by its sheer simplicity, 'make the decision' for the secretary. By asking if the injury was treated by first aid, doctor, hospital or not treated at all, combined with the questions asking for a brief description of the injury and what subsequent treatment was given, it was reasoned that most eventualities would be catered for without laying down difficult rules for secretaries to follow before recording an accident. For instance, if a player was hurt but went on playing, not realizing the seriousness of his injury, he would not receive treatment at the time of his accident but subsequently he would and so would be recorded. In short, an injury was an injury if the player said it was.

\section{Findings}

The 696 association football clubs who replied had an estimated 6120 accidents during the season. If all the clubs had replied the estimated number of accidents would have been 14078 . The 117 rugby football clubs had an estimated 1944 accidents and if all the clubs had replied the estimated number would have been 3888 .

These figures cover only those clubs which are listed in the handbooks for each sport. However, the pattern of injuries shown by the $\mathbf{8 1 3}$ clubs in both sports who took part in the survey are strong enough to suggest that they are representative of the sports as a whole.

\section{Site and Type of Injury}

In association football $15 \%$ of the injuries were to the INJURY RATES FOR EACH SITE

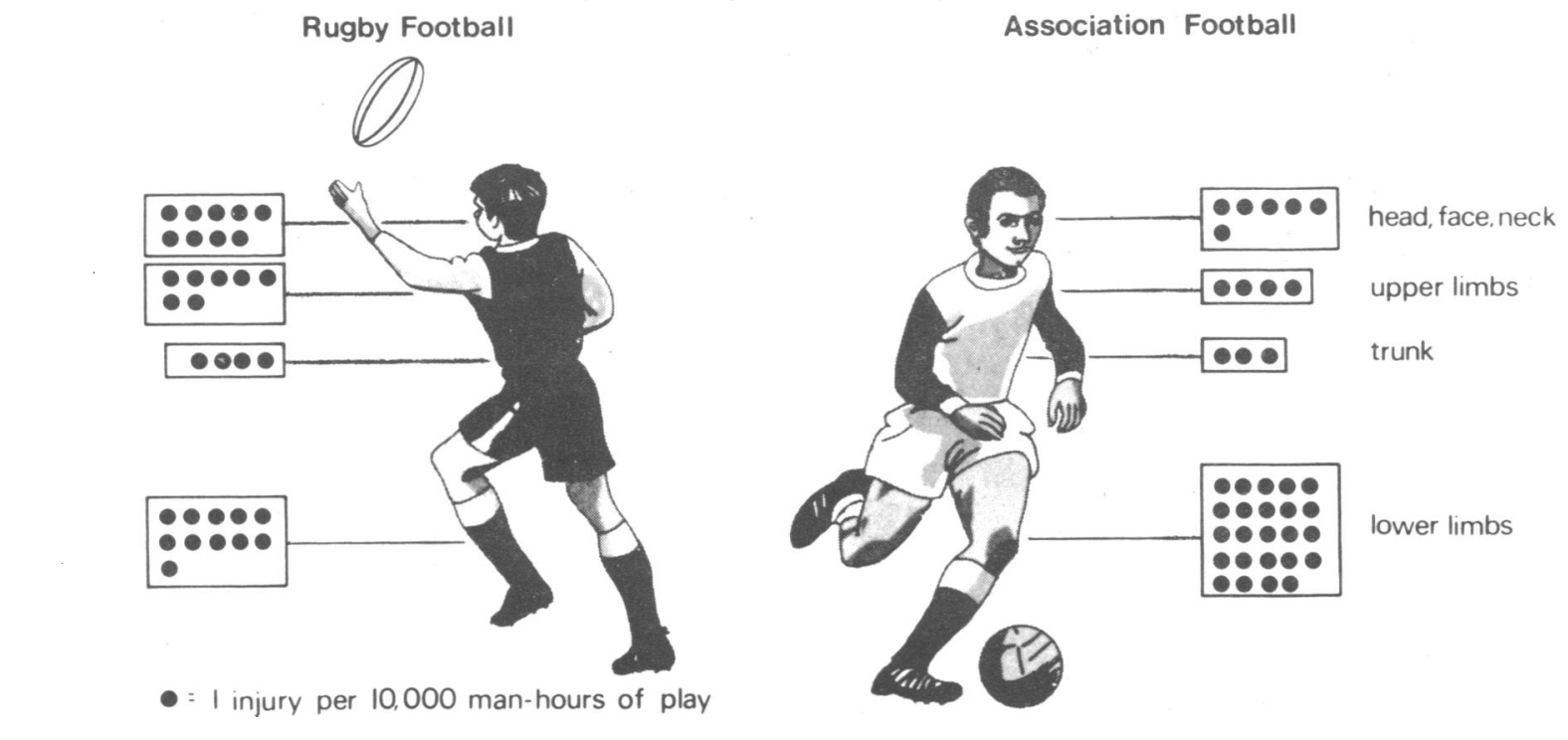

head, face or neck (Table I) and in rugby football $30 \%$. Most of the injuries to this area were cuts or bruises. Rugger caused almost twice as great a proportion $(28.8 \%)$ of fractures and dislocations of the jaws as did soccer $(13.7 \%)$ and it also caused the only cases of broken teeth and "haemorrhage behind the eye" of which there were nine examples. To the shoulder girdle and upper limbs, rugger caused a greater proportion of fractures $(54.2 \%)$ than did soccer $(38 \%)$; there were similar proportions of cuts and bruises in both sports, but fewer strains and sprains to rugby players. The injury patterns to the middle area of the body were alike in the two games, but they were different in the legs, since soccer players sustained proportionately more cuts and bruises, but only half as many strains and sprains, Table I. The number of accidents per 10,000 man hours of play, was calculated for each sport; association football (both professional and amateur combined) had a rate of 36.5 injuries per 10,000 man hours of play, compared to rugby's 30.5. The figure shows the injury rate at each site for both sports. In the four professional association football clubs surveyed, the rate was only 17.4, compared to 37.2 for amateur. Professional footballers, however, needed 14 days off play per injury, compared with only 6 days for amateur. Professional footballers, therefore, have fewer, but more serious, injuries than amateurs. Rugby footballers had rather more injuries to the upper parts of the body, but markedly fewer to the lower limbs with a rate of 10.9 accidents per 10,000 man-hours of play to them, compared to 23.8 in association football. Rugby football is more traumatic in respect of fractures, concussion and broken teeth, but compared with soccer has rather fewer minor injuries. The rugby footballer tends to get injured more above the waist but less below it, than does the soccer player, (see figure). 338 out of 696 association football clubs $(49 \%)$ who contributed to the survey had no accidents to report during the season studied, compared with 44 out of 117 rugby clubs, (38\%). 


\section{The Medical Attention Given to the Players}

Table II shows the medical attention given to the players at the time of the accident. A footnote to the table explains the overlapping of treatments. The medical attention which was given to the players at the time of the accident was a function, partly of what was available (in the case of first aid), and partly of the severity of the injury. Rugby players received a smaller proportion of first aid alone, $(35.2 \%$ of all injuries) than association football players (64.5\% of all injuries), but a greater proportion of attention by doctor or hospital for injuries at all sites at the time of the accident, Table II. Just over $18 \%$ of association football injuries did not even receive first aid, and even the $16 \%$ of fractures and dislocations received no help on the field, either because no first aid was available or because the seriousness of the injury was not recognized. In the final analysis when later and additional treatment to injuries was taken into account, it was found that the total loading on the different sources of medical care, and the numbers receiving no medical attention at any time (if all the clubs had replied) would have been:

TABLE 1: Types of Injuries at 4 Grouped Sites

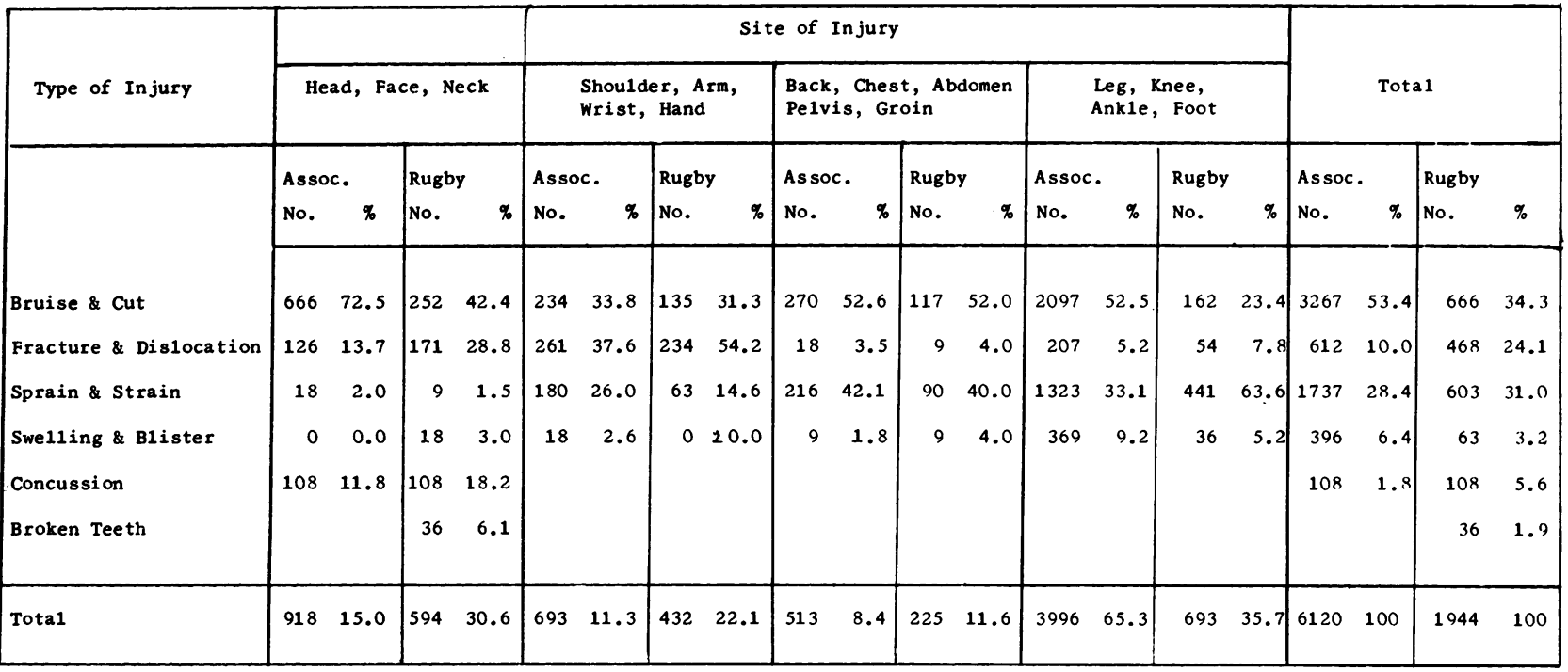

TABLE 2: Types of Injuries by Medical Attention given at Time of Accident

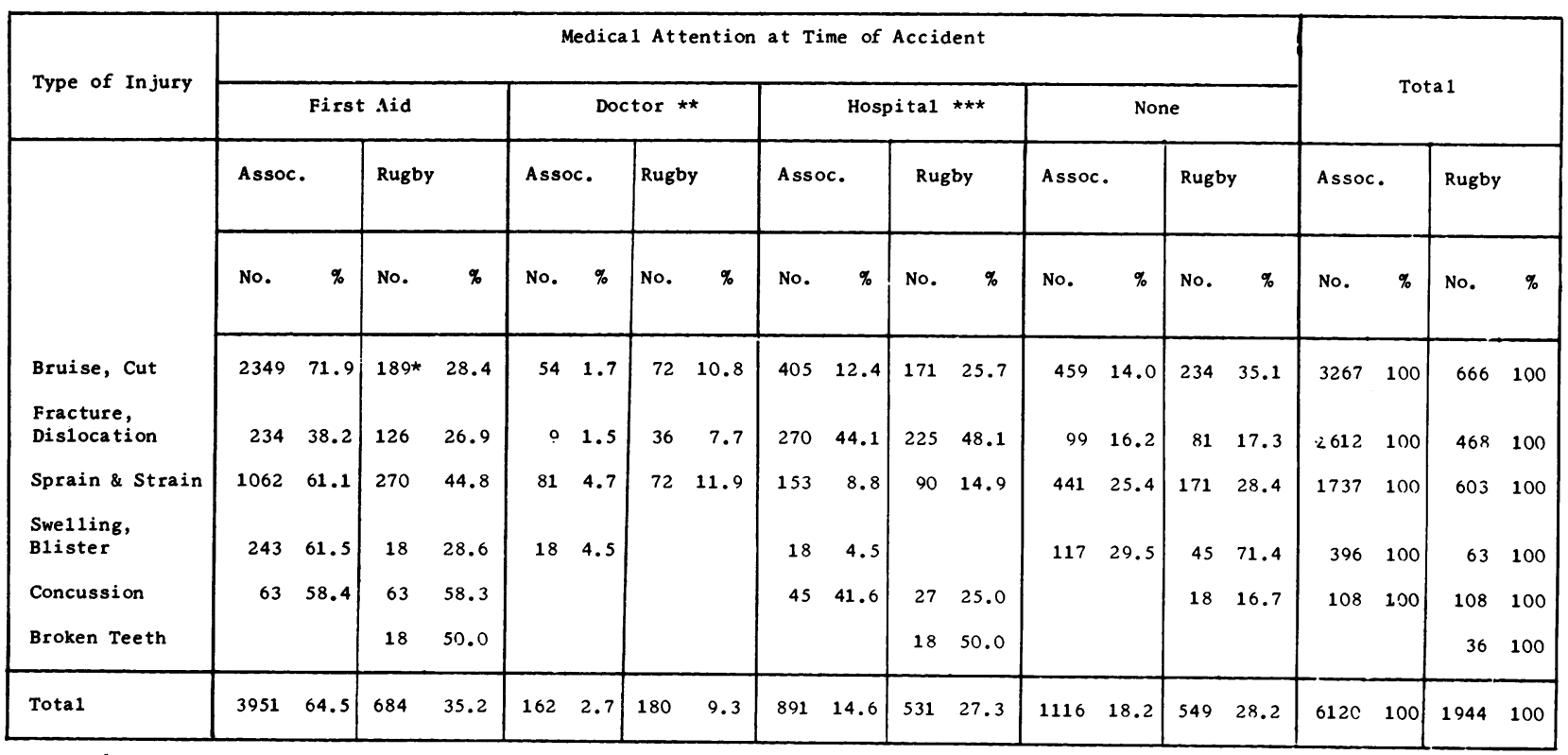

-Nine of these were haemorrhage behind the eye.

-.. 'Includes 'hospital alone' and 'hospital and first aid' and 'hospital and doctor' and 'hospital and doctor and first aid'. 


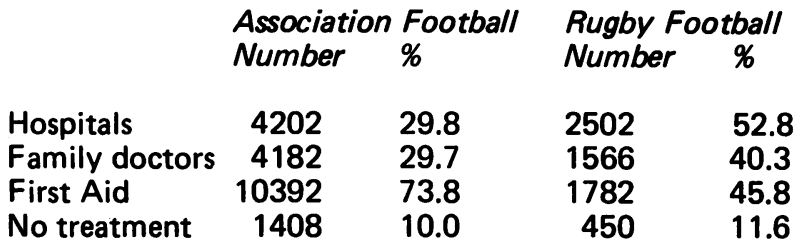

All the four professional clubs who took part in the survey had their own doctors compared with only $3 \%$ of the amateur clubs.

The median time needed off play for an injury to recover is shown in Table III. For each site the rugby footballer takes a longer time to get back to play, and in general, taking all sites together, it is twice as long, which again suggests that if a rugby player is injured at all, it is rather more severe than in the case of an association footballer. But, even so, very few of the absences are very long, which suggests a high degree of motivation in the players. Our impression is that the time taken off accurately reflects real loss of bodily function.

The opinions of the club secretaries on the adequacy of medical attention at the time of the injury in respect of its site and type were recorded as also was the kind of medical attention which was given. The secretaries of association football clubs felt that $82.8 \%$ of injuries covering all sites were adequately managed on the field, but their enthusiasm declined from feeling that, whereas all the blisters were well treated, only $57 \%$ of the dislocations were. The rugby secretaries, however, were about $10 \%$ more satisfied, since they felt that as many as $92.1 \%$ of the injuries of their players were well cared for, with very little difference of opinion between the types of injury. What the secretaries thought about the different combinations of medical attention at the time of injury, was also recorded, but they voiced very little difference between treatments. It is a sobering thought to record that on the face of it, they felt that a doctor was only $2.8 \%$ more adequate than a first aid man; since $90 \%$ of the doctors' attention seemed satisfactory to them, compared to $87.2 \%$ of the first aiders', but this difference is too small to be really meaningful. Rugby football secretaries felt rather more enthusiastic than their association counterparts about every form of treatment, which their players had received. The strongest complaints of all secretaries were when no treatment was available on the field.

\section{Discussion}

Both types of football are fairly safe games and in the more popular sport of association football, a player can expect at least one injury in every $2 \frac{1}{2}$ seasons and in rugby one injury in every 5 seasons. It should be remembered that a rugby injury is likely to be more serious than a soccer injury. The absolute numbers of injuries which occur during the season are a reflection of the popularity of the sports. But, it can be argued that it would be both unwise and unnecessary to make the sports safer as it would remove the risk ingredient, which, mixed with the elements of activity, skill and competition, make the right prescription for so many men. Life is not long enough to demonstrate everything statistically, but it is not an implausible hypothesis to suppose that there may be an inverse relationship between organized sport and the disorganized violence which is an increasing problem of our age. On the other hand, Geiringer (1971) makes two points which command attention. First, that the natural demands which sport makes should be made and satisfied by normal every day life. For primitive man with his life, violent, brutish and short, they most certainly were, but not for the modern sedentary, telly-watching, wheel-borne man. But, Geiringer may well be right in saying that we should re-introduce a greater component of physical activity into every day life. The evidence upon the inverse relationship between physical activity and heart attacks supports this, as also does the less well-documented evidence, linking regular physical activity with temperamental stability. This author's second point leaves us with a slightly uneasy feeling. In effect, he asks:- "What happens to the sportsman who has given up?" - to the man who has become used to a large calorie intake and who gives up the exercise but keeps up the intake. If it proved practicable to identify, isolate and follow up such a group, it might be worth doing. But, it must be remembered that sport is a temporary business of the young and active period of life. A better, and more positive approach would be to teach young men how to live the rest of their lives rather than to discourage sport as suggested by Geiringer.

Table III

Median time off play per injury by the site of injury for both sports

Site of Injury Median time off play per injury (days)

Association football Rugby football

$\begin{array}{lll}\text { Head and face } & 3 & 8\end{array}$

Shoulder, arm wrist and hand

Back, chest, abdomen, pelvis and groin

Leg, knee, ankle, foot 7

All sites 6 
The present study, however, prompts two practical suggestions. It was the opinion of club secretaries that the immediate treatment of association and rugby football injuries would be much improved if there were more trained first aiders either as team members or on the touch line. The strength of this point is increased where there are several football games going on near each other as often happens in many big towns, in parks or open spaces. It may well be worth taking a "leaf out of industry's book" as the two situations have something in common. Here the aim is to give first aid cover to each shift with trained first aiders from among the workers themselves.

It may be that the time has come to consider improving the types of clothing worn during play. In soccer and rugger the jersev and shorts have changed very little since the games began. Vulnerable areas of the body are quite unprotected from inevitable blows and kicks. With the modern materials available today, a possible suggestion for a simple, protective garment is a body stocking in fine material, the upper part constituting the present shirt, with the legs lined from ankle to thigh with a dense light-weight padding. The padding could be slit or hinged behind the knee to allow freedom of movement. Shorts could be worn over the garment.

In soccer most injuries are to the lower limbs and more than half are bruises and cuts. Ankles and knees are particularly vulnerable and protective padding over these sites would absorb much of the impact. The all-in-one garment could be light weight and flexible with the compact protection built in. Injuries to the shoulders of rugby players might also be reduced by the use -of padding.

The best way to find out whether or not such a garment would reduce the large numbers of cuts and bruises with the consequent loss of play and work and the cost of medical attention they cause, would be to conduct a controlled trial. A number of teams might volunteer to wear the new type of garment and their accident rate could be compared with similar teams wearing the conventional jersey and shorts.

But, a balance would have to be struck between this suggestion and leaving things as they are, keeping in mind that the chances of any individual player being injured are few, and that a reasonable compromise should be made between protection for the player and making him feel coddled.

\section{Acknowledgements}

Acknowledgements are due to the Sports Council, Chairman Roger Bannister, C.B.E., D.M., F.R.C.P., for financial assistance for the survey.

\section{REFERENCES}

BANNISTER, Roger, Sport, Physical Recreation, and the National Health. British Medical Journal, 1972, 4, $711-715$.

GEIRINGER, E., Sport as a Threat to Physical and Mental Health. Bulletin of Physical Education, 1972, p. 19. 